\title{
Practice-oriented estimation of the seismic demand hazard using ground motions at few intensity levels
}

\author{
Brendon A. Bradley*,† \\ Department of Civil and Natural Resources Engineering, University of Canterbury, Private Bag 4800, Christchurch, \\ New Zealand
}

\begin{abstract}
This paper examines the calculation of the seismic demand hazard in a practice-oriented manner via the use of seismic response analyses at few intensity levels. The seismic demand hazard is a more robust measure for quantifying seismic performance, when seismic hazard is represented in a probabilistic format, than intensity-based assessments, which remain prevalent in seismic design codes. It is illustrated that, for a relatively complex bridge-foundation-soil system case study, the seismic demand hazard can be estimated with sufficient accuracy using as little as three intensity measure levels that have exceedance probabilities of $50 \%, 10 \%$ and $2 \%$ in 50 years which are already of interest in multi-objective performance-based design. Compared with the conventional use of the mean demand from an intensity-based assessment(s), it is illustrated that, for the same number of seismic response analyses, a practice-oriented 'approximate' seismic demand hazard is a more accurate and precise estimate of the 'exact' seismic demand hazard. Direct estimation of the seismic demand hazard also provides information of seismic performance at multiple exceedance rates. Thus, it is advocated that if seismic hazard is considered in a probabilistic format, then seismic performance assessment, and acceptance criteria, should be in terms of the seismic demand hazard and not intensity-based assessments. Copyright (C) 2013 John Wiley \& Sons, Ltd.
\end{abstract}

Received 21 November 2012; Revised 28 April 2013; Accepted 3 May 2013

KEY WORDS: $\quad$ seismic demand hazard; multi-objective seismic performance assessment; intensity-based assessment

\section{INTRODUCTION}

Earthquake-induced ground motion hazard can be prescribed in a scenario-based or probability-based manner [1-3]. A probabilistic representation of ground motion hazard, as conventionally computed from probabilistic seismic hazard analysis, comprises all potential earthquake ruptures, which pose a ground motion hazard to the site considered, the likelihood of rupture occurrence and the uncertainty in the consequent ground motion at a site. The so-called seismic hazard curve, one result of probabilistic seismic hazard analysis, provides the rate [2] (or probability [4]) of exceedance of the ground motion intensity measure (IM) considered. Thus, the (continuous) seismic hazard curve illustrates that all ground motion $I M$ values in its domain can occur, although obviously some with a greater likelihood than others.

Despite the fact that a seismic hazard curve provides information for a continuum of $I M$ values, it is common to assess seismic performance on the basis of the seismic response of the system considered to ground motions conditioned on a single $I M$ value. Such a seismic performance

*Correspondence to: Brendon A. Bradley, Department of Civil and Natural Resources Engineering, University of Canterbury, Private Bag 4800, Christchurch, New Zealand.

†E-mail: brendon.bradley@ canterbury.ac.nz 
assessment at a single value of the conditioning $I M$ is referred to as an intensity-based assessment herein. For example, current seismic design guidelines (e.g. [5-8]) prescribe seismic performance criteria on the basis of the mean seismic demand obtained from an ensemble of ground motions scaled to a 'target' (often the inappropriate uniform hazard spectrum $[9,10]$ ) for a given exceedance rate. However, the results of an intensity-based assessment have several fundamental limitations for use in seismic performance assessment [11]. Firstly, by definition, the distribution of seismic demand (or so-called engineering demand parameter (EDP)) from an intensity-based assessment, $f_{E D P I I M}\left(e d p \mid i m_{y}\right)$, is conditional on ground motions with $I M$ values of $I M=i m_{y}$ from the seismic hazard curve at a desired exceedance rate $\left(\lambda_{I M}\left(i m_{y}\right)=y\right)$. Thus, although the seismic hazard curve directly provides information on the likelihood of a certain level of ground motion being exceeded (i.e. $\lambda_{I M}\left(i_{y}\right)=y$ ), no direct information on the unconditional exceedance of the demand, $E D P=e d p$, can be obtained from $f_{E D P I I M}\left(e d p \mid i m_{y}\right)$, because a specific value of $E D P=e d p$ can be exceeded by ground motions with intensity different than $I M=i m_{y}$. Secondly, the distribution of seismic demand from an intensity-based assessment, $f_{E D P I I M}\left(e d p l i m_{y}\right)$, for an $I M$ value with a given exceedance rate, $\lambda_{I M}\left(i m_{y}\right)=y$, is not unique, but is in fact a function of the particular conditioning $I M$ considered $[12,13]$.

Similar to the ground motion $I M$ hazard, $\lambda_{I M}$, the seismic demand hazard, $\lambda_{E D P}$, directly provides the exceedance rate of some seismic demand metric for a continuum of values. The seismic demand hazard is computed by integrating the ground motion $I M$ hazard and the distribution of seismic demand versus ground motion $I M$ obtained from multiple $I M$ levels. As such, the seismic demand hazard considers the multiple potential causal earthquake ruptures; the likelihood of rupture occurrence; uncertainty in the consequent ground motion (as contained in the ground motion $I M$ hazard); and the uncertainty in the consequent seismic response. Furthermore, unlike intensity-based assessments, the seismic demand is independent of the choice of the conditioning IM [12].

Because of the aforementioned conceptual benefits of the seismic demand hazard as a demand-based metric for seismic performance assessment, it has become increasingly utilised in earthquake engineering research (e.g. [12-22]). Such research endeavours, however, as exemplified by the cited references, typically use a large number of ground motion $I M$ levels, and ground motions per $I M$ level, resulting in the requirement of hundreds, sometimes thousands, of seismic response analyses. Because such a large number of analyses are not feasible in many practical situations, it may therefore seem that the computation of the seismic demand hazard is something reserved for only high-importance engineered structures in practice.

Attempts to simplify PBEE methodologies have been previously considered [23-29]. Such examples, however, consider simplified solutions of the methodologies based on analytical idealizations. In contrast, simplified implementation of PBEE methodologies can also be considered via an exact solution of the governing equations, but a simplification in the required input data. For example, Eads et al. [30] illustrated how the collapse hazard can be efficiently computed by simply reducing the number of required analyses to define the collapse fragility curve, whereas others (e.g. [31, 32]) have utilised simplified seismic response analysis methods.

The aim of this paper is to examine the accuracy with which the seismic demand hazard can be estimated using significantly fewer IM levels than those that have been considered in previous research. The next section outlines further theoretical and practical details for computing the seismic demand hazard. The case study of a bridge-foundation-soil system, used to provide empirical results, is then described. Following this, the error introduced as a result of interpolation and extrapolation of the EDPIIM relationship based on seismic response analyses at few $I M$ levels is illustrated. The effect of error in the EDP|IM relationship on the computed seismic demand hazard is then examined for a multitude of $E D P \mathrm{~s}$ and conditioning IMs. Finally, the errors resulting from this 'practice-oriented' approximate calculation of the seismic demand hazard are compared with 'worst-case' intensity-based assessments [11], which involve performing intensity-based assessments with multiple conditioning $I M \mathrm{~s}$ in an attempt to circumvent the non-uniqueness of an intensity-based assessment with a single conditioning $I M$. 


\section{SEISMIC DEMAND HAZARD COMPUTATION}

\subsection{Theory of the demand hazard}

Formally, the seismic demand hazard, $\lambda_{E D P}(e d p)$, provides the rate of exceedance of a specific level of seismic demand, $E D P=e d p$, and can be computed following the intensity-based approach from (e.g. [12])

$$
\lambda_{E D P}(e d p)=\int_{0}^{\infty} P_{E D P \mid I M}(e d p \mid i m)\left|\frac{\mathrm{d} \lambda_{I M}(i m)}{\mathrm{d} I M}\right| \mathrm{d} I M
$$

where capitalised symbols represent variables, whereas lower case symbols represent realisations of their capitalised counterpart; $P_{E D P I I M}(e d p \mid i m)$ is the probability that $E D P>e d p$ given $I M=i m$, which can be obtained directly from the probability density function, $f_{E D P \mid I M}(e d p l i m)$; and $\lambda_{I M}(\mathrm{im})$ is the seismic hazard curve, which provides the rate of exceedance of $I M>i m$.

The computation of the seismic demand hazard via Equation (1) is shown graphically in Figure 1. Figure 1(a) illustrates that for each value of $I M$ considered in the integral, the derivate of the hazard curve is computed. The absolute value of the derivative (which is negative) is required because the hazard curve is conventionally expressed as an 'exceedance curve' rather than a 'non-exceedance curve'. Figure 1(b) illustrates that the EDP|IM relationship is obtained on the basis of performing seismic response analysis for numerous values of $I M$ and recording the value of the EDP considered. It is commonly justified that the $E D P \mid I M$ distribution is lognormal, and hence, for each $I M$ level considered, the distribution parameters (mean, $\mu$, and standard deviation, $\sigma$ ) are obtained via statistical inference. To compute the value of $P_{E D P I M}(e d p l i m)$ at $I M$ levels other than that for which seismic response analyses are computed as part of the integration, some form of interpolation/ extrapolation is required, as elaborated upon subsequently. Hence, as depicted graphically in Figure 1(b), it can be seen that the seismic demand hazard requires the specification of the EDP|IM relationship over a continuum of $I M$ values, and thus, multiple $I M$ levels at which seismic response analyses are required. Figure 1(b), for example, contains the results of seismic response analyses at 11
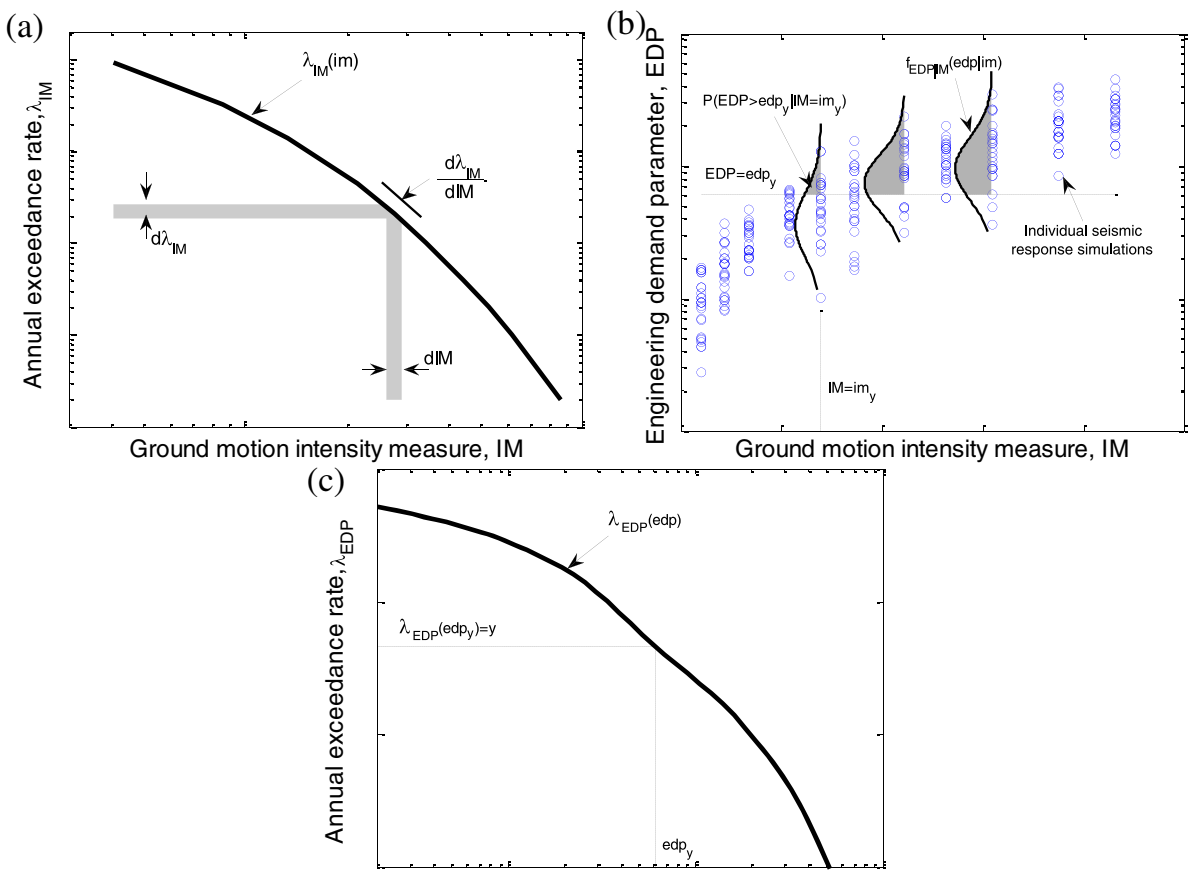

Engineering demand parameter, EDP

Figure 1. Schematic illustration of the calculation of the seismic demand hazard: (a) ground motion intensity measure $(I M)$ hazard, $\lambda_{I M}(\mathrm{im})$; (b) distribution of seismic demand conditional on various intensity measure values, $f_{E D P I I M}(e d p l i m)$; and (c) the computed seismic demand hazard, $\lambda_{E D P}(e d p)$. 
different $I M$ levels (with 25 ground motions per $I M$ level). Thus, in comparison with considering the seismic response at only a single $I M$ level via a single intensity-based assessment, the computation of the seismic demand hazard in this example involves 11 times the number of seismic response analyses to be conducted (and therefore also 11 times the number of ground motion to be selected for these analyses). As elaborated upon subsequently, the number of $I M$ levels, which is required for an accurate computation of the demand hazard, is a critical consideration and is thus the focus of this paper.

\subsection{Practical computation of the seismic demand hazard}

To understand the requirements for the practical computation of the seismic demand hazard via Equation (1), it is useful to consider the six sources of error, which can occur in this computation ([12], p. 1430):

(1) interpolation of the seismic hazard curve, $\lambda_{I M}(\mathrm{im})$;

(2) selection of ground motions;

(3) lognormal assumption of the distribution of EDPIIM;

(4) interpolation/extrapolation of the mean and variance of $E D P \mid I M$;

(5) uncertainty in the mean and variance of $E D P \mid I M$ due to the finite number of seismic response analyses performed;

(6) numerical approximation of the continuous demand hazard integral.

As noted by Bradley [12], error source 6 is minimised via appropriate numerical integration algorithms and tolerances (e.g. [33]). It should be noted that the direct numerical solution of Equation (1) is trivial, and that because approximate analytical solutions are both inaccurate and require additional effort to fit idealised relationships, they are therefore not recommended for quantitative use [26]. Error sources 2 and 3 can be considered as methodology-type uncertainties. Error source 2 will be statistically insignificant if ground motions are selected appropriately using the generalized conditional intensity measure (GCIM) approach [9, 34]. Error source 3 is usually negligible as the lognormal approximation is generally appropriate for the distribution of EDPIIM (e. g. $[14,35-37])$. The remaining error sources 1,4 and 5 are therefore those that relate directly to the computational costs of performing the seismic hazard and seismic response analyses.

Error source 1 can be minimised if the seismic hazard curve is provided at a sufficiently large number of $I M$ levels, which is practical because the computational cost of doing so is typically several orders of magnitude less than that required for performing numerous seismic response analyses [12]. If the seismic hazard curve is provided by an external third party (e.g. http:// geohazards.usgs.gov/hazardtool/), then the analyst may not have the option of obtaining $\lambda_{I M}(\mathrm{im})$ at many points. However, $\lambda_{I M}(\mathrm{im})$ is typically a 'very smooth' function (i.e. the first derivative changes slowly with $I M$ ), because it is the result of a probabilistic calculation with large uncertainties, and therefore, usually a sufficient number of points are given for error source 1 to be unimportant.

Error sources 4 and 5 are the principal hindrance in the computation of the seismic demand hazard, because seismic response analyses are significantly more computationally demanding than calculation of the seismic hazard curve. In this paper, particular attention is given to the effect of error source 4 resulting from the interpolation (and extrapolation) of the mean and variance of EDPIIM based on performing seismic response analyses at only a few IM levels. To examine this error source, 'approximate' results, based on the use of seismic response analyses at only a few IM levels, will be compared with the 'exact' results, based on the use of a large number of IM levels. Obviously, attention to the number of ground motion records considered at each $I M$ level is also of importance (i.e. error source 5), but is beyond the scope of the current paper.

\section{CASE STUDY CONSIDERED}

To adequately assess the accuracy of the demand hazard computed using seismic response analyses at a small number of intensity levels, it is necessary to consider a seismic response problem which is nontrivial. As such, the seismic response of a bridge-foundation-soil system in which the 
foundation soils are susceptible to liquefaction is examined here. The specific bridge-foundation-soil seismic response model considered represents the transverse direction of the Fitzgerald Avenue bridge in Christchurch, New Zealand. Several previous seismic response analysis studies have been performed for this structure, in both the transverse [12, 38] and longitudinal [39] directions. In the following comparisons of calculated demand hazard curves, the seismic response analysis results presented in the work of Bradley [12] are directly utilised, and therefore, the reader is directed to the work of Bradley [12], and references therein, to obtain further detail on the geometry of the system and the modelling of its various components.

The seismic response of the case study structure was considered via a total of 1650 seismic response analyses, comprising [12]:

(1) six different conditioning $I M \mathrm{~s}$ (peak ground acceleration, peak ground velocity, 0.5 -s spectral acceleration $(\mathrm{SA}(0.5)), \mathrm{SA}(1.0)$, spectrum intensity $(S I)$ and cumulative absolute velocity $(C A V))$;

(2) 11 different $I M$ levels for each conditioning $I M$ (corresponding to exceedance rates with Poisson exceedance probabilities of $99 \%, 80 \%, 50 \%, 20 \%, 10 \%, 5 \%, 2 \%, 1 \%, 0.5 \%, 0.2 \%$ and $0.1 \%$ in 50 years);

(3) 25 ground motions considered for each IM level.

Six conditioning $I M \mathrm{~s}$ were considered to illustrate the effect of this $I M$ choice on the results; however, in practice, analysts would utilise only a single conditioning $I M$. For each of the analyses considered, the seismic response of the system was quantified using a variety of $E D P \mathrm{~s}$ [12]. Here, the analysis results for four different $E D P$ s will be considered: (i) the peak displacement of the ground surface in the free field, $U_{\mathrm{FF}}$; (ii) the peak displacement of the foundation pile head, $U_{\mathrm{PH}}$; (iii) the peak curvature in the pile foundations, $\phi_{\mathrm{P}}$; and (iv) the peak acceleration of the bridge deck, $a_{\mathrm{D}}$

The distribution $P_{E D P I I M}(e d p l i m)$ in Equation (1) is obtained on the basis of statistical inference of the results from seismic response analyses. Note that global collapse of the case study structure (identified by numerical instability in the analysis) was not observed. If global collapse is significant in other cases, $P_{E D P I I M}(e d p l i m)$ should be obtained by considering collapse and non-collapse cases separately [40].

As previously noted, it was not the intention of this paper to examine the error in the seismic demand hazard resulting from the finite number of ground motion considered for each $I M$ level. Therefore, it should be noted that the use of 25 ground motions per $I M$ level is such that the resulting error in the demand hazard is relatively small, as illustrated in the work of Bradley [12], and hence, errors resulting from the number of $I M$ levels can be generally considered separate from those which would be incurred using a smaller number of ground motions per $I M$ level.

The seismic response analyses for the 66 different $I M$ levels were based on ground motions selected using the GCIM approach [9,34], which is explicitly consistent with the seismic hazard considered. When making the subsequent comparisons between the seismic demand metrics from intensitybased assessments and the seismic demand hazard, it is critical that both have been obtained on the basis of a consistent method of ground motion selection. As noted by Bradley [12], consistent ground motion selection ensures that the demand hazard will be statistically independent of the conditioning $I M$ selected.

Finally, it should be noted that in addition to the uncertainty in the seismic response resulting from ground motion uncertainty, there is also uncertainty due to the idealised modelling of the system via the adopted seismic response analysis model. This uncertainty is not directly considered herein, although the errors in the demand hazard resulting from the error in the EDPIIM relationship due to (i) ground motion or (ii) ground motion and numerical model uncertainty are likely to be similar (because the latter will inevitably simply result in a larger uncertainty in $f_{E D P I M}(e d p l i m)$ ). Such an assertion can be validated in future research.

\section{PARAMETRISING EDPIIM FROM SEISMIC RESPONSE ANALYSES AT A LIMITED NUMBER OF IM LEVELS}

As previously noted, computation of the seismic demand hazard requires that the EDPIIM relationship be prescribed over a continuum of $I M$ values. However, in a practical context, seismic response 
analyses will be performed at only a limited number of $I M$ levels (e.g. Figure 1(b)). Thus, computation of $P_{E D P I I M}$ requires interpolation (and extrapolation) at all other $I M$ values required in the demand hazard calculation.

Interpolation and extrapolation of the EDPIIM relationship, for the purposes of computing the demand hazard, can be performed in two general ways. Firstly, the value of $P_{E D P I I M}$ can be obtained directly on the basis of the interpolation/extrapolation of values computed at each of the $I M$ levels considered. Secondly, the parameters of the distribution, $f_{E D P I I M}$ (i.e. $\mu_{\ln E D P \mid I M}$ and $\sigma_{\ln E D P I I M}$ for a lognormal distribution), can be interpolated/extrapolated on the basis of the parameter values at each of the $I M$ levels considered, and the value of $P_{E D P I I M}$ is obtained subsequently from the lognormal assumption. The problem with the former approach is that $P_{E D P I M}$ is difficult to interpolate/extrapolate because of the following: (i) relatively large highorder derivatives; and (ii) although $P_{E D P I I M}=[1,0]$ for the limiting cases of $I M=[0, \infty]$, these bounds are not useful in practice because such limiting cases are not of concern. For these reasons, the second and more common approach of interpolating $\mu_{\ln E D P I I M}$ and $\sigma_{\ln E D P \mid I M}$ will be considered herein.

There are various interpolation and extrapolation methods that can be used to provide estimates of a function based on observations at a discrete set of points, such as polynomial or spline interpolation. Because the number of different $I M$ levels that will be considered here is small, such as two or three $I M$ levels (as desired from a practical viewpoint), and because there is no need for continuity of first and higher derivatives of the EDPIIM relationship, attention is restricted to piecewise linear interpolation. The results to follow were also considered using alternative interpolation functions, with minimal differences found. Thus, simple piecewise linear interpolation is considered appropriate for practical computation.

\subsection{Interpolation and extrapolation of $\mu_{\ln E D P \mid I M}$}

Previous parametric functions for the central tendency of the EDPIIM relationship have often been of a power model form, such that the relationship between $\ln (E D P)$ and $\ln (I M)$ is linear (e.g. [21, 24, 41]). Although it is acknowledged that such a functional form has been principally utilised because it allows a closed-form solution of the demand hazard (and that such analytical solutions can be significantly erroneous, as previously noted), it will be used herein for piecewise interpolation. That is, the equation for interpolation of the lognormal mean is given by

$$
\begin{aligned}
\mu_{\ln E D P \mid I M}(i m) & =\ln \left(a_{i}\right)+b_{i} \ln (i m) \quad i m_{i} \leqslant i m<i m_{i+1} \\
b_{i} & =\frac{\ln \left(\frac{\mu_{i+1}}{\mu_{i}}\right)}{\ln \left(\frac{i m_{i+1}}{i m_{i}}\right)} \quad ; \quad a_{i}=\exp \left[\mu_{i}-b_{i} \ln \left(i m_{i}\right)\right]
\end{aligned}
$$

where $\ln ()$ is the natural logarithm of its argument and $\mu_{i}$ is shorthand for $\mu_{\ln E D P I I M}\left(i m_{i}\right)$, where $i m_{i}$ is the $I M$ level at which seismic response analyses have been performed and the lognormal mean computed. Note that the notation of the constant coefficient in the piecewise interpolation has been kept as $\ln \left(a_{i}\right)$ so that the median of the distribution $E D P_{50} \mid I M=\exp \left(\mu_{\ln E D P \mid I M}(i m)\right)=a_{i} i m^{b_{i}}$.

Some extrapolation of the EDPIIM relationship may also be required if the seismic demand hazard is required for exceedance rates which are similar to the rates of the maximum and minimum $I M$ levels considered. Needless to say, extrapolation errors are generally larger than interpolation errors; therefore, care should be exercised in the maximum and minimum exceedance rates of the demand hazard, which are considered reasonable. To allow for some level of extrapolation, the interpolation function for the first and last piecewise segments is simply extended. Figure 2(a) provides a schematic illustration of the interpolation and extrapolation of the lognormal mean seismic demand. 


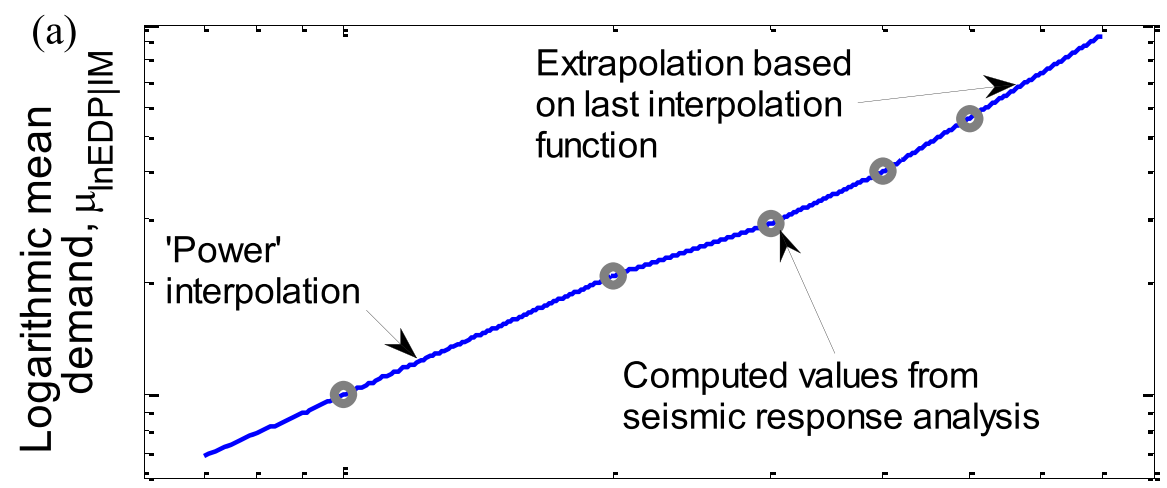

$\log$ (Intensity measure, IM)

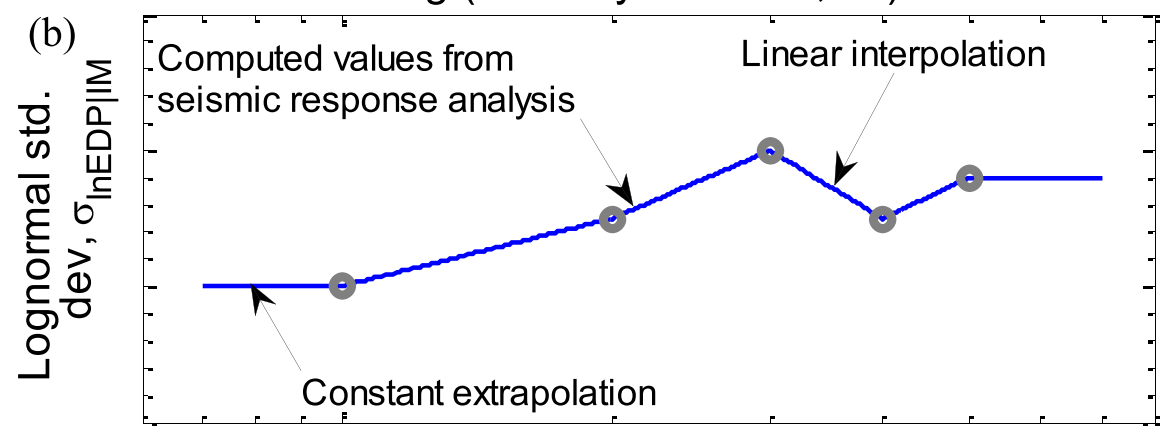

$\log$ (Intensity measure, IM)

Figure 2. Interpolation and extrapolation of the EDP|IM relationship between $I M$ levels at which seismic response analyses are performed: (a) the lognormal mean and (b) the lognormal standard deviation.

\subsection{Interpolation and extrapolation of $\sigma_{\ln E D P} \mid I M$}

The lognormal standard deviation is assumed to follow a piecewise linear variation between IM levels in logarithmic space, given by

$$
\begin{aligned}
\sigma_{\ln E D P \mid I M}(i m) & =c_{i}+d_{i} \ln (i m) \\
d_{i} & =\frac{\sigma_{i+1}-\sigma_{i}}{\ln \left(\frac{i m_{i+1}}{i m_{i}}\right)} \\
c_{i} & =\sigma_{i}-d_{i} \ln \left(i m_{i}\right)
\end{aligned}
$$

where $\sigma_{i}$ is shorthand notation for $\sigma_{\ln E D P \mid I M}\left(i m_{i}\right)$, where $i m_{i}$ is the $I M$ level at which seismic response analyses have been performed and the lognormal standard deviation computed. For the purposes of extrapolation, the standard deviation was taken as a constant and equal to the calculated value at the maximum or minimum IM level considered. Figure 2(b) provides a schematic illustration of the interpolation and extrapolation of the lognormal standard deviation.

\subsection{Parametric EDPIIM errors using two IM levels from case study results}

To illustrate the adequacy of the parametric form of the $E D P \mid I M$ relationship, it is instructive to consider the seismic response analysis data from the case study structure for several EDP and IM combinations. Results are firstly considered for the situation in which seismic response analyses are performed at only two different $I M$ levels, taken here to be those corresponding to $I M$ exceedance rates which have $10 \%$ and $2 \%$ in 50-year exceedance probabilities. Results will also be subsequently considered for three different $I M$ levels, where the third $I M$ level considered is that which has a $50 \%$ in a 50-year exceedance probability. These IM levels were selected because they are commonly adopted in multi-objective performance-based design and/or assessment, with the 
ground motion levels corresponding to these exceedance probabilities denoted as 'Frequent', 'Design' and 'Maximum Considered' in FEMA350 [42], for example, and similar naming elsewhere [43, 44].

Figure 3 illustrates the adequacy of the parametric approximation based on two $I M$ levels for the relationship between peak pile curvature, $\phi_{p}$, and either $S A(0.5)$ (i.e. Figure $3(\mathrm{a}-\mathrm{c})$ ) or $S I$ (i.e. Figure 3(b-d)). In Figure 3(a, b), individual seismic response analysis results are shown with individual data points at all 11 IM levels, as well as the exact piecewise function based on all of these 11 IM levels. Also shown is the approximate results based on using only two $I M$ levels. As expected, it can be seen that the error resulting from extrapolation increases as the $I M$ value of interest deviates from the two $I M$ levels upon which the parametric form is based. This is particularly the case in Figure 3(b) for the $\phi_{\mathrm{p}}-S I$ relationship, which can be seen to be significantly underpredicted based on the linear (in log-log space) approximation. Although there are differences at the single $I M$ level at which interpolation is performed (corresponding to an exceedance probability of $5 \%$ in 50 years), it can be seen that they are minor in relation to those resulting from extrapolation.

Figure 3(c, d) illustrates the lognormal standard deviation computed at the 11 IM levels for which seismic response analyses were performed. Also shown is the parametric approximation of the standard deviation, which is obtained on the basis of using only two IM levels. It can be seen that while the standard deviations fluctuate with $I M$ level, they fall within a relative narrow range, in comparison with the general increase in the lognormal mean demand with increasing $I M$ level. As a result, it can be clearly seen in Figure 3(c, d) that the use of a constant standard deviation for extrapolation is appropriate and that the use of linear extrapolation would result in large errors, and possibly even negative values.

With regard to bias resulting from extrapolation, it can be seen that for the $\phi_{\mathrm{p}}-S A(0.5)$ relationship in Figure 3(a), the linear approximation for the mean results in an overprediction at small $I M$ values, although such an approximation results in an underprediction of the $\phi_{\mathrm{p}}-S I$ relationship in Figure 3(b). This indicates that an overprediction or underprediction in extrapolation is not a function of the EDP considered (both of which are $\phi_{\boldsymbol{p}}$ in Figure 3(a,b)). Similarly, Figure 4(a, b) illustrates the adequacy of the linear approximation for two cases with the same conditioning $I M$ (i.e. $C A V$ ), but different $E D P$ s, with overprediction for small $C A V$ values in Figure 4(a), but little bias in Figure 4(b). Thus, it can also be seen that there is no systematic overprediction or underprediction dependent on the choice of the
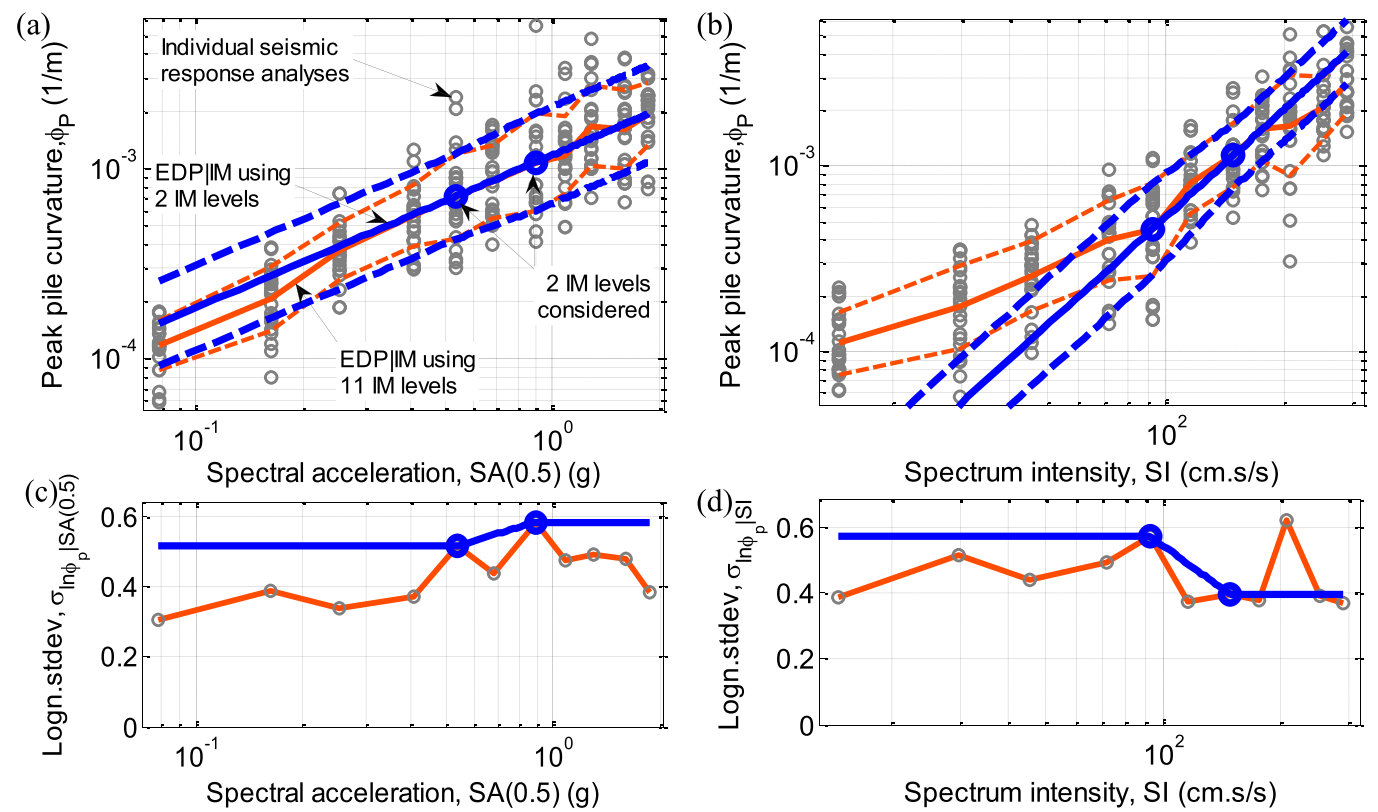

Figure 3. Comparison between the case study seismic response analysis results, the exact piecewise variation in distribution parameters based on all 11 IM levels and the approximate variation in distribution parameters based on two IM levels, for the same EDP but different conditioning $I M$ s. (a, b) illustrate the median, 16th and 84th percentiles; (c, d) illustrate the lognormal standard deviation. 


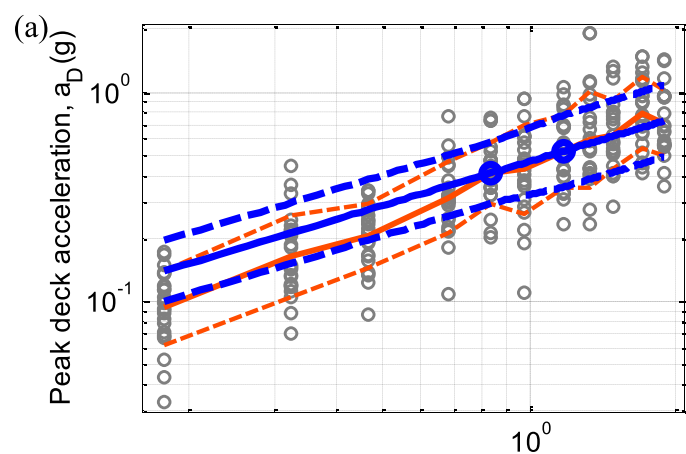

(c)

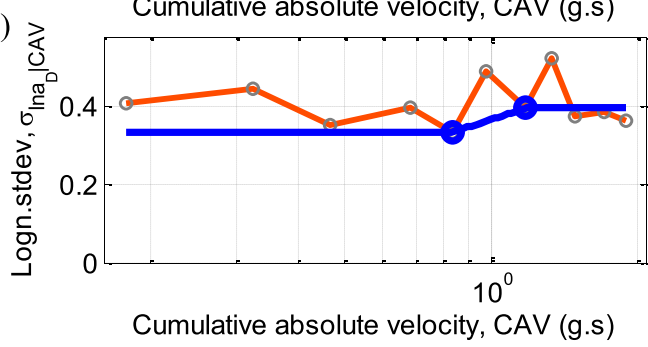

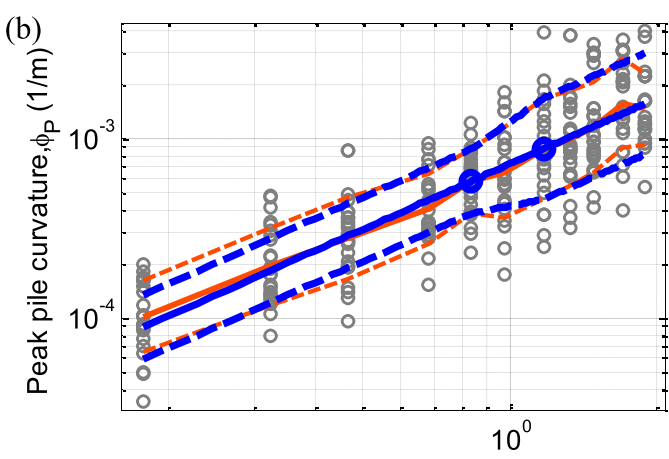

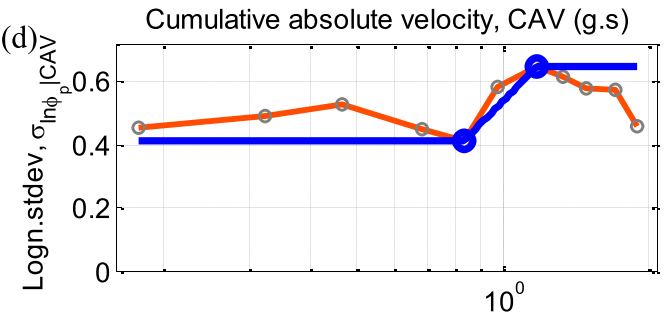

Cumulative absolute velocity, CAV (g.s)

Figure 4. Comparison between the case study seismic response analysis results, the exact piecewise variation in distribution parameters based on all $11 I M$ levels and the approximate variation in distribution parameters based on two IM levels, for different EDPs but the same conditioning $I M$. (a, b) illustrate the median and 16th and 84th percentiles; (c, d) illustrate the lognormal standard deviation.

conditioning $I M$. Hence, when seismic response analyses are performed at a limited number of $I M$ levels, it is not possible to estimate the sign of the extrapolation error, and one can only note that the magnitude of the error is likely to increase with increasing extrapolation.

\subsection{Parametric EDPIIM errors using three IM levels from case study results}

In the previous paragraphs, it was seen that the principal problem with the parametric form for the $E D P I I M$ relationship was based on extrapolation. Because the two $I M$ levels considered were those related to the $10 \%$ and $2 \%$ in 50-year exceedance probabilities, the extrapolation error was particularly large for significantly greater exceedance probabilities, which are also of relevance in seismic performance assessment. Logically, it is therefore desirable to consider the use of three $I M$ levels, where the third $I M$ level considered is that corresponding to an exceedance probability of $50 \%$ in 50 years.

Figure 5 illustrates the same EDPIIM plots shown in Figures 3 and 4, but with the approximate $E D P \mid I M$ distribution based on three $I M$ levels. Because the interpolation/extrapolation is piecewise, the predictions for the exceedance probabilities less than $10 \%$ in 50 years (i.e. the 'middle' $I M$ level) are unchanged. It can be seen that the addition of the third $I M$ level improves the piecewise prediction for the EDPIIM distribution in all cases, particularly those in Figure 5(b, c), where the slope of the piecewise interpolation segments vary noticeably. Although figures are not explicitly provided for the variation in the lognormal standard deviation based on three $I M$ levels, it can be relatively easily seen from examining Figures $3(\mathrm{c}, \mathrm{d})$ and $4(\mathrm{c}, \mathrm{d})$ that the addition of third $I M$ levels would also notably improve the parametric approximation of the standard deviation over the full $I M$ range of interest.

\subsection{Error in parametric EDPIIM relation for all case study results}

Figures 3-5 illustrated the errors associated with the piecewise approximation of the EDPIIM relationship using seismic response analyses based on only two or three $I M$ levels for a subset of the total number of $24 E D P \mid I M$ combinations (i.e. four $E D P \mathrm{~s}$ and six conditioning $I M \mathrm{~s}$ ) that exist in the case study data. Here, the errors for all of these EDPIIM combinations are considered to enable a 

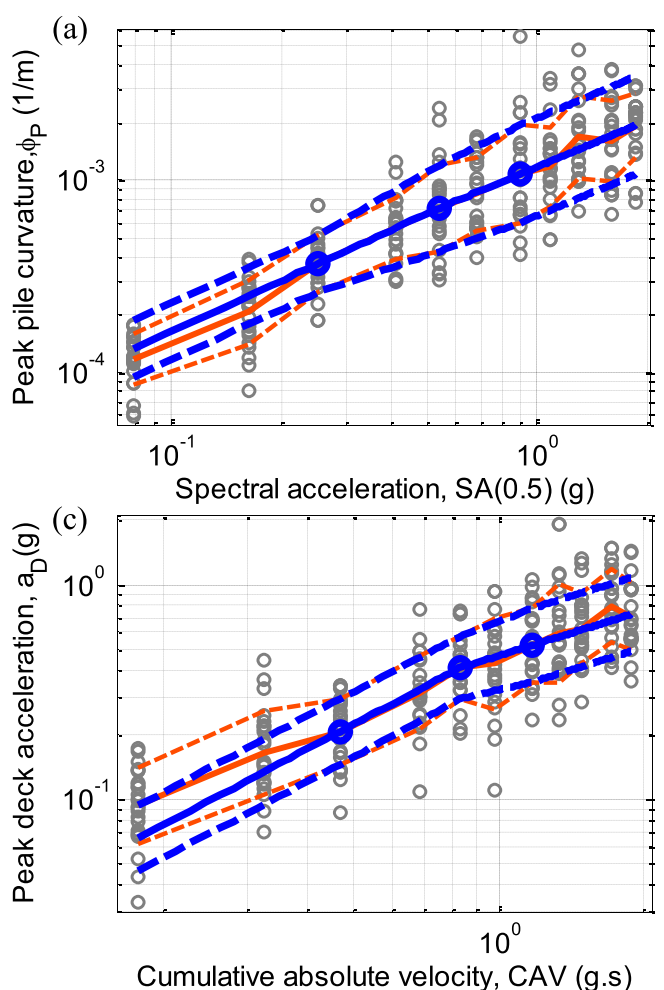
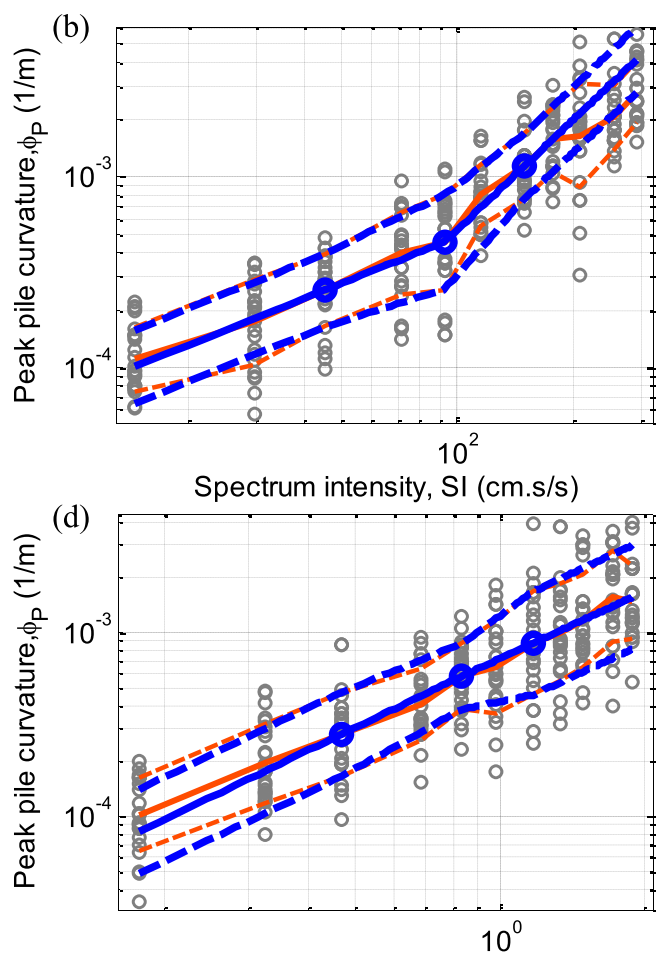

Cumulative absolute velocity, CAV (g.s)

Figure 5. (a-d) Comparison between the case study seismic response analysis results, the exact piecewise variation in distribution parameters based on all $11 \mathrm{IM}$ levels and the approximate variation in distribution parameters based on three $I M$ levels. In each subpanel, the parametric distribution is illustrated via the median and 16th and 84th percentiles.

more direct examination of the error in the mean and standard deviation. To consider multiple EDPs in a single figure, it is necessary to present the errors between the exact results (i.e. those directly obtained on the basis of $11 I M$ levels) and the approximate results (i.e. those based on two or three $I M$ levels and then interpolated/extrapolated to other $I M$ values) in the form of error ratios. The error ratio in the median of the EDPIIM distribution is obtained from the ratio between the exponentials of the lognormal means, that is, $\exp \left(\mu_{\ln E D P \mid I M}^{\text {observed }}\right) / \exp \left(\mu_{\ln E D P \mid I M}^{\text {predicted }}\right)$. Similarly, the error ratio in the standard deviation of the EDPIIM distribution is obtained from $\sigma_{\ln E D P \mid I M}^{\text {observed }} / \sigma_{\ln E D P \mid I M}^{\text {predicted }}$. To plot these error ratios for different conditioning $I M \mathrm{~s}$, the exceedance rate of the $I M$ level is utilised.

Figure 6 illustrates the error ratios in the median and standard deviation of the EDPIIM distribution for the 24 different $E D P \mid I M$ combinations of seismic response analysis results. It can be firstly noted that, by definition, there is no error in the median and standard deviation at the $I M$ levels considered in developing the piecewise interpolation/extrapolation (i.e. an error ratio of 1.0). As was noted with respect to the subset of results shown in Figures 3 and 4, Figure 6(a) illustrates that when two IM levels are considered, the largest error in the prediction of the median corresponds to exceedance rates significantly greater than the lower error of the two $I M$ levels (i.e. $I M$ values for which $\lambda_{I M} \gg 10 \%$ in 50 years). At the smallest $I M$ level considered (corresponding to a $99 \%$ in a 50 -year exceedance probability), it can be seen that the average error ratio in the median $E D P \mid I M$ value is approximately 2.5 , with the 84 th percentile error ratio equal to approximately 5.0 . In contrast, it can be seen that there is no significant error in the median EDPIIM when extrapolating to exceedance probabilities rarer than the larger error of the two $I M$ levels considered, with the average error ratio close to 1.0 and of relatively small variation. Partially as a result of this difference in the median error ratios for extrapolation above and below the two $I M$ levels shown in Figure 6(a), it will be subsequently seen that the seismic demand hazard is very poorly predicted at exceedance rates greater than those corresponding to these two IM levels. 

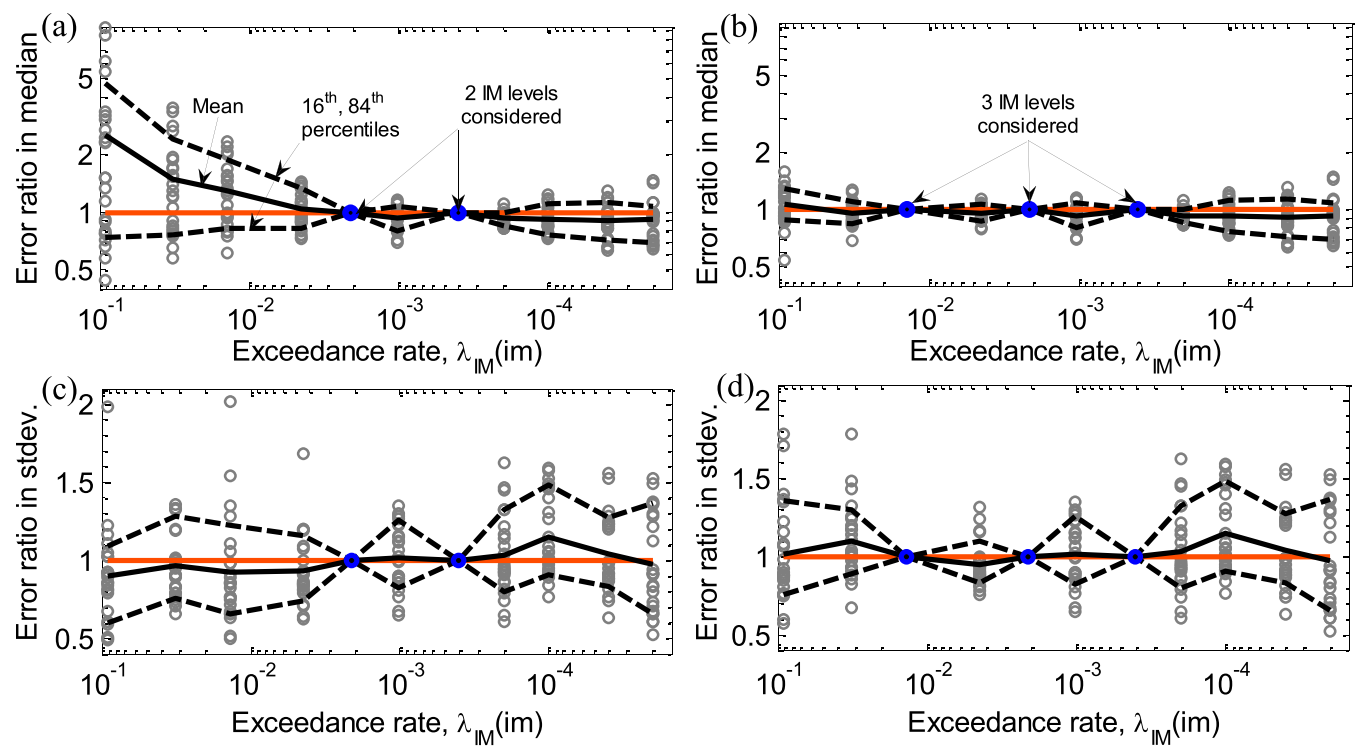

Figure 6. Error ratios in the lognormal mean and standard deviation of the parametric EDP|IM distribution for all $24 E D P \mid I M$ combinations in the case study results for $(\mathrm{a}, \mathrm{c})$ two $I M$ levels and $(\mathrm{b}, \mathrm{d})$ three $I M$ levels. The different $I M$ levels are denoted by their hazard exceedance rate to plot different conditioning $I M \mathrm{~s}$ on the same axis.

Figure 6(b) illustrates the error ratio in the median value of the EDPIIM relationship based on considering seismic response analyses at three $I M$ levels. As previously noted, because the parametric EDPIIM relationship is considered in a piecewise manner, the results in Figure 6(a,b) are identical for $I M$ levels with exceedance rates less than the middle of the three $I M$ levels considered. It can be seen that the addition of the third $I M$ level, corresponding to an exceedance rate with $50 \%$ probability of exceedance in 50 years, leads to a significant reduction in the error ratios for more frequent exceedance rates, as compared with those based on using only two IM levels. Although not as immediately obvious, there is also an improvement in the error ratio at an exceedance rate of 0.0044 , which is based on extrapolation when using only two $I M$ levels (Figure 6(a)), but interpolation when using three $I M$ levels (Figure 6(b)).

Figure 6(c, d) illustrates the error ratios in the standard deviation of the EDPIIM relationship based on the use of two and three $I M$ levels, respectively. It can be seen that the use of a third $I M$ level reduces the error ratio in the standard deviation at more frequent exceedance rates, but the reduction is not as noticeable as that for the median in Figure 6(a,b).

\section{ESTIMATION OF THE DEMAND HAZARD USING FEW IM LEVELS}

Having examined the errors in the EDPIIM relationship resulting from interpolation and extrapolation to $I M$ values other than those at which seismic response analysis was performed, it is now appropriate to directly examine the consequent errors in the demand hazard. It should be reiterated that, in theory, the demand hazard is unique, irrespective of the choice of the conditioning IM [12]. Such a result was shown to be achievable in a practical context using the same seismic response analyses considered in this study based on 11 IM levels [12]. It will be seen that the use of seismic response analysis from a limited number of (two or three) IM levels leads to a larger variation in the demand hazard computed on the basis of different conditioning IMs. Thus, for reference, the range of exact seismic demand hazard values based on 11 IM levels from the work of Bradley [12] will be provided for comparison with the results presented here based on two of three $I M$ levels. This is because the error resulting from the interpolation/extrapolation of the EDPIIM relationship (referred to as error source 4 previously) is the only difference between the results to follow and those of Bradley [12]. 


\subsection{Demand hazard estimation using two IM levels}

Figure 7(a, c) illustrates the estimation of the seismic demand hazard for peak pile curvature, $\phi_{\mathrm{p}}$, and peak deck acceleration, $a_{\mathrm{D}}$, respectively, based on using seismic response analyses at only two $I M$ levels (corresponding to $10 \%$ and $2 \%$ exceedance in 50 years). For comparative purposes, the exceedance rates of the two IM levels in parametrising the EDPIIM relationship are shown, as well as the range of the exact seismic demand hazard computed on the basis of using $11 I M$ levels[12]. Figure 7(b, d) illustrates the error ratios in the computed demand hazard $E D P$ values for a given exceedance rate, that is, Error ratio in $E D P=e d p^{\text {exact }} / e d p^{\text {approx }}$, where $\lambda_{E D P}^{\text {exact }}\left(e d p^{\text {exact }}\right)=\lambda_{E D P}^{\text {approx }}\left(e d p^{\text {approx }}\right)$.

Figure 7 illustrates that, as expected, the error in the estimation of the demand hazard is smallest for exceedance rates in the vicinity of those $I M$ levels which the EDPIIM relationship is developed from. The errors in the demand hazard for exceedance rates greater than $\lambda=2.1 * 10^{-3}$ (i.e. corresponding to $10 \%$ in 50 years) can be seen to increase drastically with increasing exceedance rate, with error ratios exceeding factors of 0.5 or 2.0 in several cases. With reference to the errors in the EDPIIM results previously discussed, it can be seen that (i) the extrapolation of the EDPIIM relationship for $\phi_{\mathrm{p}} \mid C A V$ (i.e. Figure 4(b)) was fortuitously very accurate, thus resulting in a computed demand hazard, which is similar to the exact values and (ii) in contrast, the extrapolation of the EDPIIM relationship for $\phi_{\mathrm{p}} \mid S I$ (i.e. Figure 3(b)) was very underconservative, resulting in a significant underprediction of the demand hazard for a given exceedance rate. At the exceedance rates equal to the two $I M$ levels considered, it can be seen that generally the error ratios are within the range of $[0.7,1.3]$. It can also be seen that this
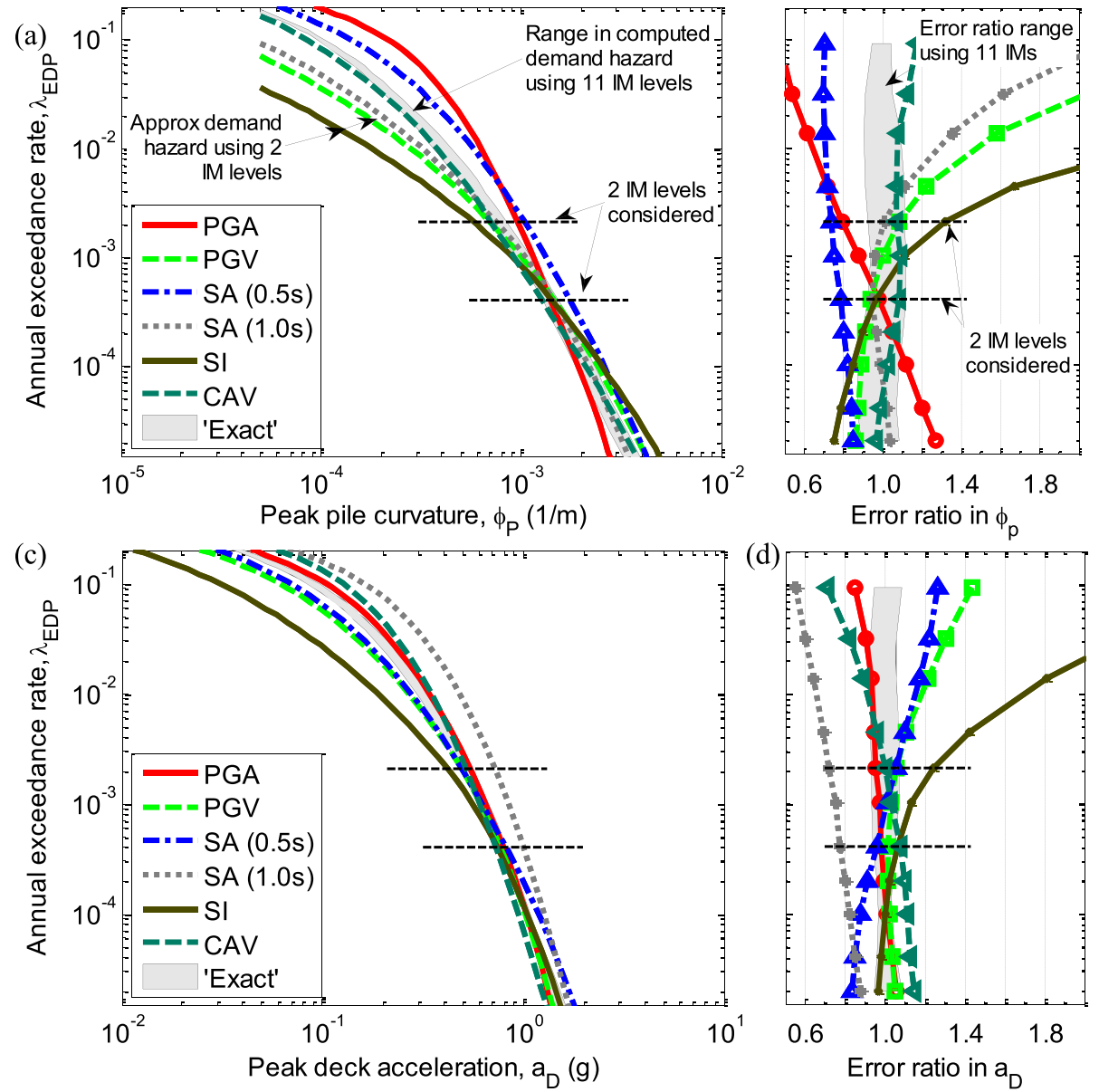

Figure 7. Illustration of the computed seismic demand hazard for two EDPs based on considering seismic response analyses at only two $I M$ levels. The range in the exact results based on considering seismic response analyses at $11 \mathrm{IM}$ levels [12] is also shown for reference. 
range in error ratio at these two exceedance rates is notably greater than that which results from the use of seismic response analyses at $11 I M$ levels, illustrating the importance of accuracy in the EDPIIM relationship over a range of $I M$ values, when performing integration, as required in Equation (1). The greater error ratios in the median EDPIIM relationship for frequent exceedance rates (i.e. Figure 6(a)), combined with the fact that the contribution toward the demand hazard integral comes principally from values of $I M$ values below the median ([26], Figure 4), is a reason the error ratios for the $I M$ level corresponding the $10 \%$ in 50 years are generally greater than those at the IM level corresponding to $2 \%$ in 50 years.

\subsection{Demand hazard estimation using three IM levels}

Figure 8 illustrates the estimation of the seismic demand hazard, and associated error ratios, for peak pile curvature, $\phi_{\mathrm{p}}$, and peak deck acceleration, $a_{\mathrm{D}}$, based on using seismic response analyses at three $I M$ levels (corresponding to 50\%, 10\% and 2\% exceedance in 50 years). By comparing Figures 7 and 8 , it is immediately apparent that the inclusion of the third $I M$ level, corresponding to $50 \%$ exceedance in 50 years, results in a significant increase in the accuracy of the computed demand hazard at frequent exceedance rates. In addition, as a result of adding a third $I M$ level, there is also a reduction in the error ratios at exceedance rates corresponding to the remaining two $I M$ levels, with error ratios at these levels now generally within $[0.8,1.2]$ (in contrast to an error ratio range of $[0.7,1.3]$ from using only two $I M$ levels as given in Figure 7). It can be seen in Figure 8(b, d) that
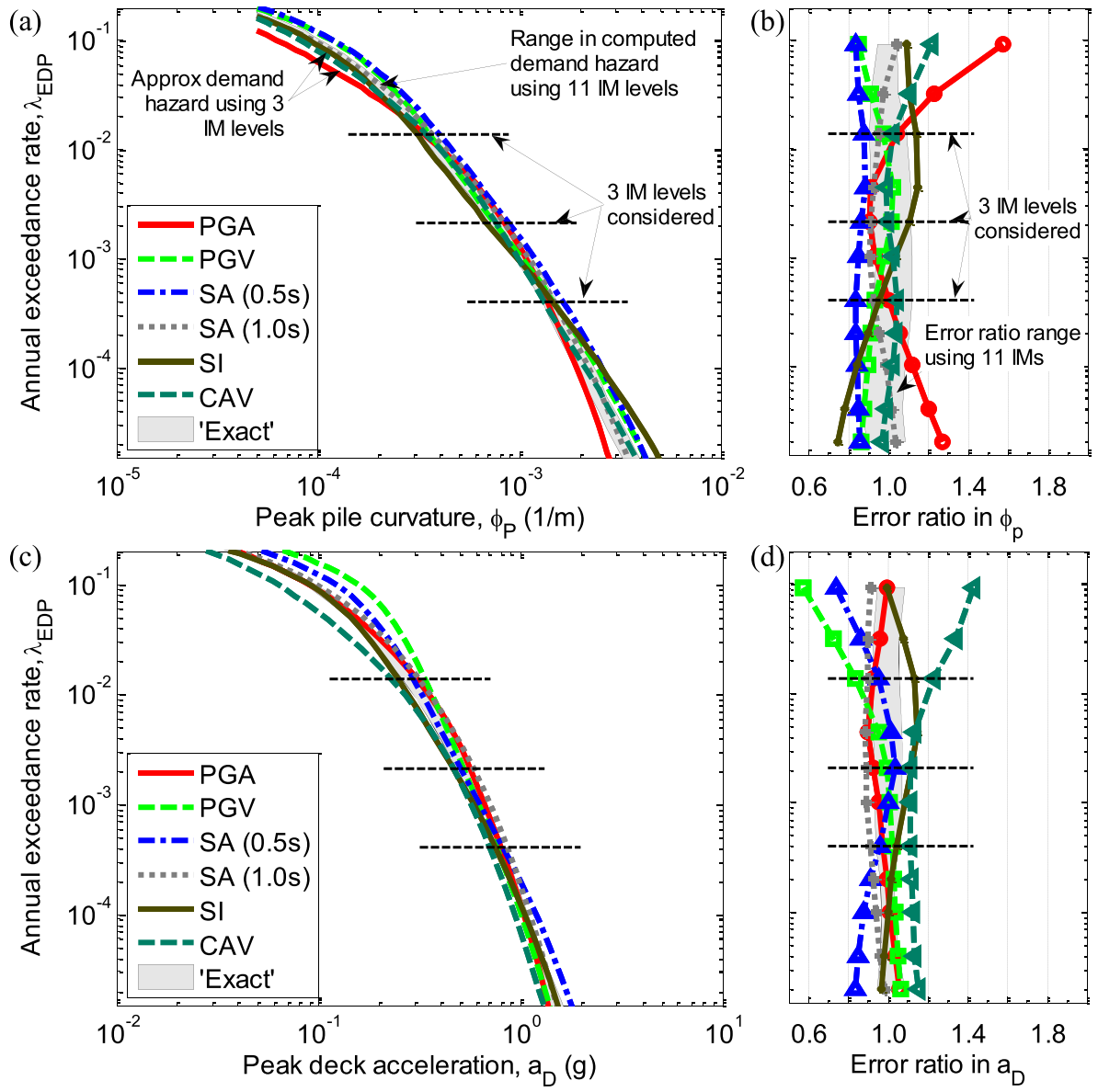

Figure 8. Illustration of the computed seismic demand hazard for two EDPs based on considering seismic response analyses at only three $I M$ levels. The range in the exact results based on considering seismic response analyses at $11 \mathrm{IM}$ levels [12] is also shown for reference. 
for all exceedance rates within the range of the three $I M$ levels considered (i.e. between rates corresponding to $50 \%$ and $2 \%$ probabilities of exceedance in 50 years), the error ratios are in the range $[0.8,1.2]$. Naturally, the error ratios increase for extrapolation of the demand hazard beyond the range of the $I M$ levels considered, although the error does not increase rapidly, indicating that a limited amount of extrapolation may be acceptable (particularly to lower exceedance rates).

\subsection{Error in the demand hazard for all case study results}

Figures 7 and 8 illustrate the error ratios in the computation of the demand hazard for two different $E D P$ s. Figure 9 illustrates the error ratios in the demand hazard as a function of exceedance rate, for all four EDPs considered in the case study structure. With a total of six conditioning $I M \mathrm{~s}$, the consideration of four $E D P$ s gives a total of 24 error ratios per exceedance rate. The mean values, 16th and 84th percentiles of the error ratios, based on the use of two of three $I M$ levels, are also given in the respective figures. For comparative purposes, the exceedance rates of the $I M$ levels in
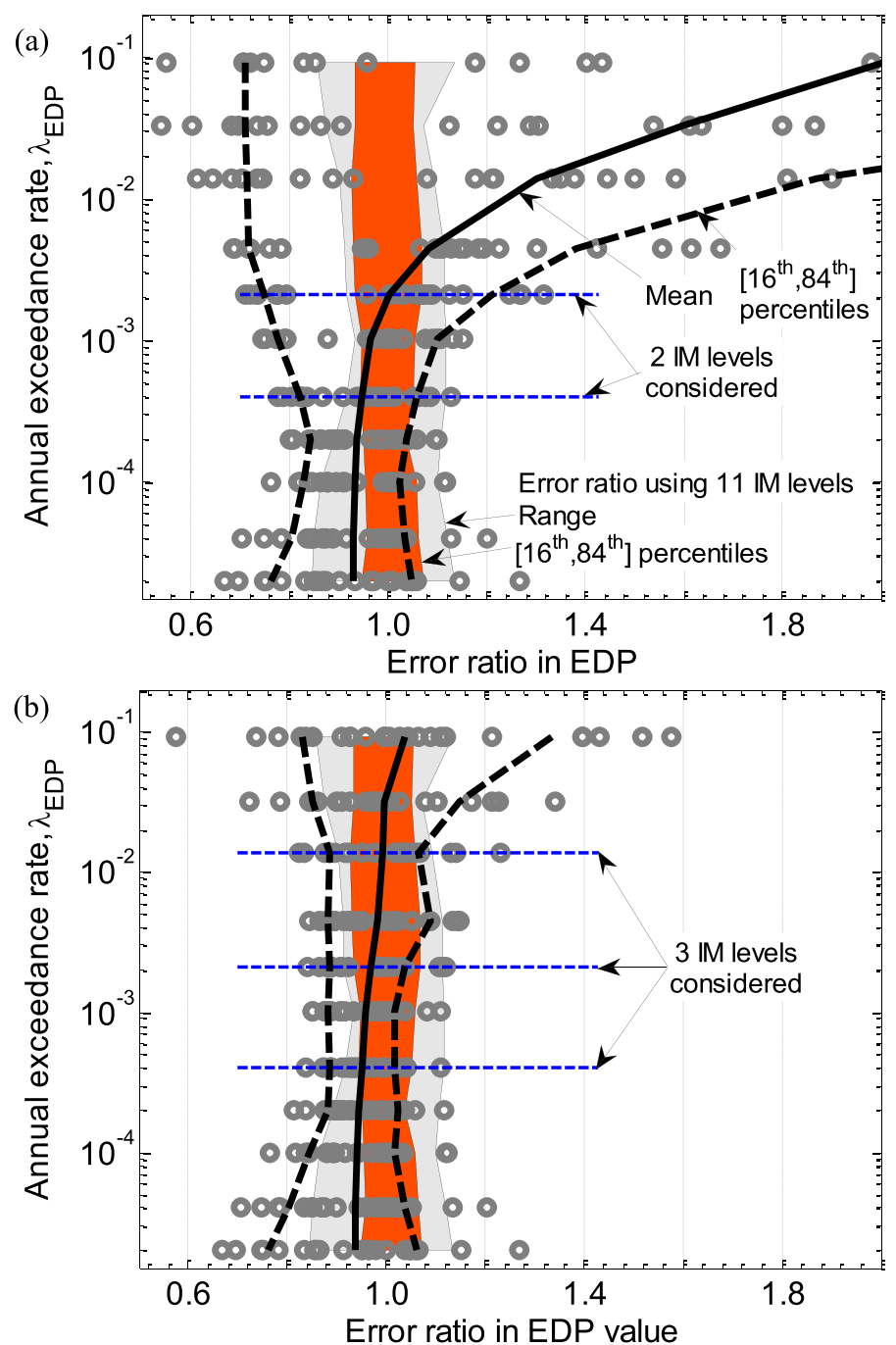

Figure 9. Error ratios in the computed seismic demand hazard for all $24 E D P$ and conditioning $I M$ combinations of the case study results: (a) using two $I M$ levels and (b) using three $I M$ levels. The range and 16th and 84th percentiles of the exact results based on considering seismic response analyses at

$11 I M$ levels [12] are also shown for reference. 
parametrising the EDPIIM relationship are shown, as well as the error ratio range and 16th and 84th percentiles of the error ratios from the exact seismic demand hazard computed on the basis of using $11 I M$ levels [12]. As noted with respect to Figure 7, it can be seen in Figure 9(a) that there is a significant error in the demand hazard for exceedance rates greater than the $10 \%$ in a 50 -year exceedance probability. Furthermore, even the error in the value of the demand hazard for the $10 \%$ in a 50-year exceedance probability is relatively large, with error ratios in the range $[0.7,1.3]$, in comparison with a range of $[0.9,1.1]$ based on exact results. Figure $9(b)$ illustrates that the addition of a third $I M$ level at an exceedance rate corresponding to $50 \%$ probability of exceedance in 50 years leads to a significant reduction in the demand hazard error ratio for these frequency exceedance rates and also provides a further reduction in the error ratios at smaller exceedance rates. Examination of the error ratio range, and the 16th and 84th percentile values of the error ratio, for exceedance rates between $50 \%$ and $2 \%$ probability of exceedance in 50 years, illustrates that there is in fact no overly significant difference between those based on three $I M$ levels and the exact results based on 11 IM levels for exceedance rates 'within' those of the IM levels considered.

Because multi-objective performance-based seismic design/assessment is often concerned with the ground motion levels corresponding to at least three different exceedance rates (e.g. denoted as Frequent, Design and Maximum Considered ground motion levels in FEMA350 [42]), and because of the notable reduction in the error in estimating the demand hazard values using three $I M$ levels compared with two $I M$ levels, it is concluded that at least three $I M$ levels should be considered for demand hazard estimation in a practical setting.

\section{COMPARISON OF APPROXIMATE DEMAND HAZARD WITH WORST-CASE INTENSITY-BASED ASSESSMENTS}

Seismic performance criteria in contemporary seismic design guidelines (e.g. [5-8]) are currently based on the mean seismic demand obtained from an intensity-based assessment (i.e. ground motions conditioned on a single $I M$ value). However, the distribution of seismic demand from an intensitybased assessment, for an $I M$ value with a given exceedance rate, is not unique but is in fact a function of the particular conditioning $I M$ considered [12, 13]. It has therefore been suggested (e.g. [13], Section 4.2.3) that one approach could be to ensure that the seismic performance is satisfactory for seismic response analyses utilising ground motion ensembles based on different conditioning IMs [11]. This logic is analogous to the consideration of different load combinations in conventional gravity design and essentially results in the seismic demand metric being the maximum of the mean seismic demands from the various intensity-based assessments considered, which will be referred to herein as a worstcase intensity-based assessment, and denoted as $\max \left[\mu_{E D P \mid I M=i m_{y}}\right]$ [11]. Given the aforementioned benefits of the seismic demand hazard metric over those based on an intensity-based assessment, it is of interest to compare the accuracy and precision of the seismic demand metric obtained from a worstcase intensity-based assessment and from direct estimation of the seismic demand hazard using few $I M$ levels, with the exact seismic demand hazard based on numerous $I M$ levels.

Bradley [11] recently compared the seismic demands obtained from worst-case intensity-based assessments with the exact seismic demand hazard for the same case study structure examined here. The worst-case intensity-based assessments were performed with ground motions having an $I M$ value with a given exceedance rate, $\lambda\left(i m_{y}\right)=y$, and compared with the value of the seismic demand hazard for the same exceedance rate, that is, $\lambda_{E D P}\left(e d p_{y}\right)=y$. Using the notation in the work of Bradley [11], the error ratio between the $E D P$ value from the exact seismic demand hazard, $e d p_{y}^{\text {exact }}$, and from the worse-case intensity-based assessment, $\max \left[\mu_{E D P \mid I M=i m_{y}}\right]$, is given by

$$
R_{e d p}^{\mathrm{IM}-\text { based }}=\frac{e d p_{\mathrm{y}}^{\text {exact }}}{\max \left[\mu_{E D P \mid I M=i m_{y}}\right]}
$$


As an equivalent to the error in the worst-case intensity-based assessments as given by Equation (4), the error in the approximate demand hazard based on seismic response analyses at a limited number of $I M$ levels shown in Figures 7-9 can be formally written as

$$
R_{e d p}^{\lambda_{E D P}}=\frac{e d p_{y}^{\text {exact }}}{e d p_{y}^{\text {approx }}}
$$

where $e d p_{y}^{\text {approx }}$ is the seismic demand from the approximate demand hazard curve based on considering a limited number of $I M$ levels. Because, as shown in Figure 9, the error ratios based on the approximate demand hazard are dependent on the exceedance rate considered, here, $R_{e d p}^{\lambda_{E D P}}$ is considered only at the exact exceedance rates corresponding to the $I M$ levels considered in the parametrisation of the EDPIIM relationship. That is, when the EDPIIM relationship is based on IM levels corresponding to the $50 \%, 10 \%$ and $2 \%$ in 50 -year exceedance probabilities, the error ratios, $R_{e d p}^{\lambda E D P}$, are considered at these three exceedance rates only to ensure an equitable comparison with the error ratios, $R_{e d p}^{\mathrm{IM}-\text { based }}$, from the worst-case intensity-based assessment.

Figure 10(a) provides a comparison between the error ratio relative to the exact seismic demand hazard of worst-case intensity-based assessments (i.e. $R_{e d p}^{\mathrm{IM}-b a s e d}$ ) and the approximate seismic demand hazard (i.e. $R_{e d p}^{\lambda_{E D P}}$ ). The results for $R_{e d p}^{\mathrm{IM}-\text { based }}$ are those directly from Bradley ([11], Figure 10). The 'number of ground motion ensembles utilised' shown on the $x$-axis is directly proportional to the number of seismic response analyses which are required, and therefore is indicative of feasibility from a practical viewpoint. For the worst-case intensity-based assessments, the number of ground motion ensembles utilised is equal to the number of different conditioning $I M$ s considered in the
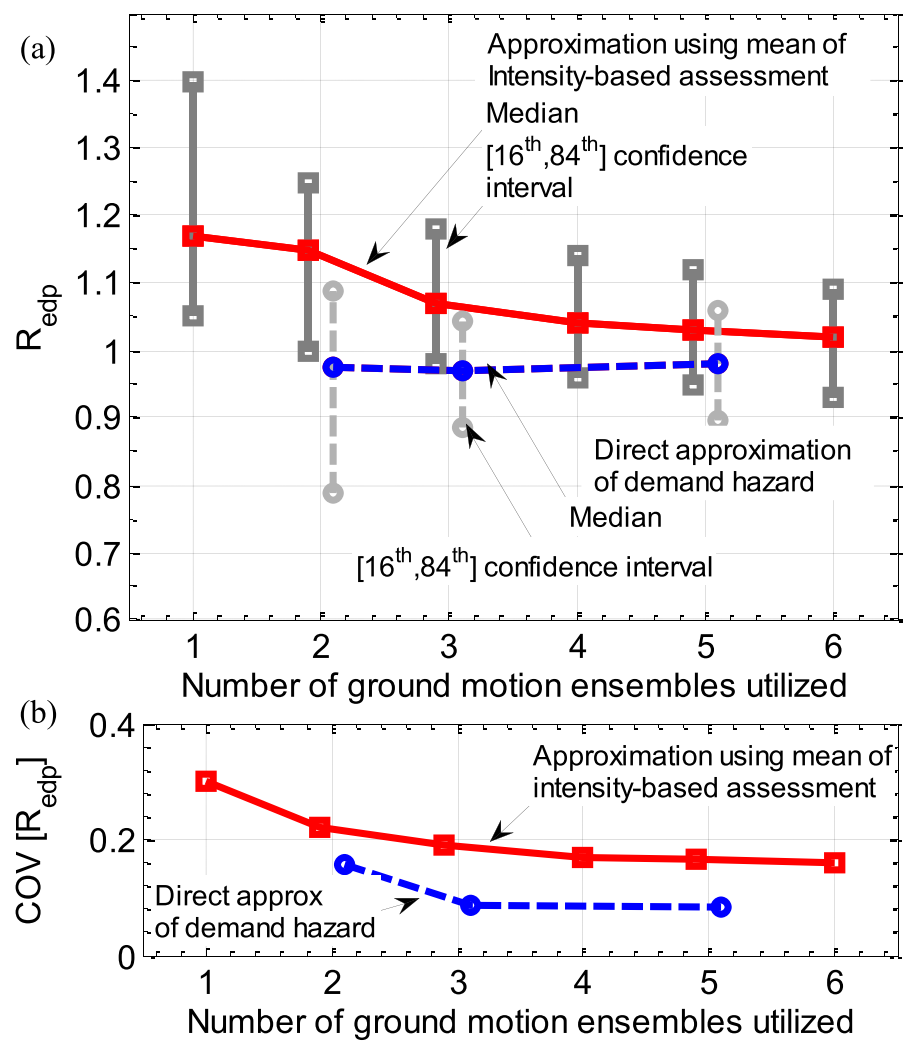

Figure 10. (a) Error ratio, relative to the actual EDP value from the demand hazard for a given exceedance rate, of the mean from a worst-case intensity-based assessment and the approximate demand hazard based on few IM levels and (b) the coefficient of variation (COV) in the error ratio. Some results are offset on the $x$-axis for clarity. 
intensity-based assessment. For the approximate demand hazard, the number of ground motion ensembles utilised is equal to the number of different $I M$ levels, which are considered in parametrising the EDPIIM relationship. It can be seen that, for a given number of seismic response analyses required, the median error ratio is consistently closer to 1.0 based on the direct approximation of the demand hazard with a limited number of IMs, as compared with that based on a worst-case intensity-based assessment. Furthermore, the variability in the error ratio, as indicated by the 16th and 84th percentile confidence interval in Figure 10(a), or the coefficient of variation in Figure 10(b), is also smaller when directly estimating the seismic demand hazard. The greater accuracy and precision of the direct approximation of the seismic demand hazard is apparent whether it be two, three or five ground motion ensembles, which are required for seismic response analyses. Although the precision of the direct approximation of the seismic demand hazard notably improves on the basis of using three $I M$ levels in comparison with two (as elaborated upon previously), it can be seen that there is a diminishing return in the increased precision when using five $I M$ levels (which were taken to be those with $50 \%, 20 \%, 10 \%, 5 \%$ and $2 \%$ probability of exceedance in 50 years). The principal reason for this is the finite sample uncertainty in the distribution parameters of the EDPIIM relationship (i.e. $\mu_{\ln E D P I I M}$ and $\sigma_{\ln E D P I I M}$ ), due to the use of 25 ground motions for each $I M$ level (e.g. [12], Figure 12).

The aforementioned results and discussion indicates that for a given number of seismic response analyses, it is better to directly approximate the seismic demand hazard and obtain the EDP value for a given exceedance rate than to utilise a worst-case intensity-based assessment. In addition to being more accurate and precise, it is also critical to understand that in estimating the seismic demand hazard, more information is provided about the seismic performance. For example, if a worst-case intensity-based assessment is performed using three different ground motion ensembles (selected on the basis of three different conditioning $I M \mathrm{~s}$ ), then this assessment will provide a seismic performance metric at the single exceedance rate for which the ground motions are considered. In contrast, in the direct approximation of the seismic demand hazard, a single conditioning $I M$ is considered, seismic response analyses are performed on the basis of ground motions selected at three different $I M$ levels and the seismic demand hazard provides a seismic performance metric for at least the three exceedance rates considered (which can be interpolated and even slightly extrapolated as shown in Figure 9 and related text). Furthermore, if seismic performance metrics based on a worst-case intensity-based assessment were required at three different $I M$ levels, then this would in fact require three times the number of seismic response analyses as direct approximation of the seismic demand hazard. Thus, for a given number of seismic response analyses, direct estimation of the seismic demand hazard for seismic performance assessment should be preferred in comparison with the use of a worst-case intensity-based assessment.

\section{CONCLUSIONS}

This paper has examined the computation of the seismic demand hazard from a practical perspective, with particular focus on the error introduced via the use of seismic response analyses performed at only a few IM levels. A case study of a bridge-foundation-soil system was used to provide empirical results to illustrate the salient features of the problem. The error in the relationship between the seismic demand and ground motion intensity, as a result of interpolation and extrapolation from the $I M$ levels at which seismic response analyses are performed, was examined, from which it was seen that extrapolation is the principal problem. It was seen that, for the case study considered, estimation of the seismic demand hazard based on two $I M$ levels, with $I M$ exceedance probabilities of $10 \%$ and $2 \%$ in 50 years, can produce approximate results within $30 \%$ error for similar exceedance rates, but errors in excess of a factor of 2 when extrapolated to more frequent exceedance rates that are often of interest. The computation of the demand hazard using seismic response analyses at three $I M$ levels, with exceedance probabilities of 50\%, 10\% and 2\% in 50 years, provided an estimate of the seismic demand hazard with error ratios within $20 \%$ or less over a wide range of exceedance rates of interest.

Compared with the conventional use of the mean demand from an intensity-based assessment(s), it was illustrated that for the same number of seismic response analyses, the seismic demand value obtained from a practice-oriented approximate seismic demand hazard is a more accurate and 


\section{B. A. BRADLEY}

precise estimate of that from the exact seismic demand hazard. Direct estimation of the seismic demand hazard also provides information of seismic performance at multiple exceedance rates, in contrast to a single intensity-based assessment. Thus, if seismic hazard is considered in a probabilistic format, then seismic performance assessment, and acceptance criteria, should be in terms of the seismic demand hazard and not intensity-based assessments.

\section{ACKNOWLEDGEMENT}

Constructive comments from Dr Matjaz Dolsek (University of Ljubljana) are greatly appreciated.

\section{REFERENCES}

1. Kramer SL. Geotechnical Earthquake Engineering. Prentice-Hall: Upper Saddle River, NJ, 1996; 653.

2. McGuire RK. Probabilistic seismic hazard analysis: early history. Earthquake Engineering and Structural Dynamics 2008; 37:329-338. DOI: 10.1002/eqe.765.

3. Bommer JJ. Deterministic vs. probabilistic seismic hazard assessment: an exaggerated and obstructive dichotomy. Journal of Earthquake Engineering 2002; 6(1 supp 1):43-73.

4. Field EH, Gupta N, Gupta V, Blanpied M, Maechling P, Jordan TH. Hazard calculations for the WGCEP-2002 forecast using OpenSHA and distributed object technologies. Seismological Research Letters 2005; 76:161-167.

5. ASCE/SEI 7-05. Minimum design loads for buildings and other structures. American Society of Civil Engineers, ASCE Standard No. 007-05, 2006; 388pp.

6. CEN. Eurocode 8: design of structures for earthquake resistance. Part 1: General rules, seismic actions and rules for buildings, Final Draft prEN 1998, European Committee for Standardization, 2003; pp.

7. FEMA-368. NEHRP recommended provisions for seismic regulations for new buildings and other structures, 2000 Edition. Part 1: Provisions, Building Seismic Safety Council for the Federal Emergency Management Agency, 2001; pp.

8. NZS 1170.5. Structural design actions, Part 5: earthquake actions - New Zealand. Standards New Zealand: Wellington, New Zealand, 2004; 82.

9. Bradley BA. A generalized conditional intensity measure approach and holistic ground motion selection. Earthquake Engineering and Structural Dynamics 2010; 39(12):1321-1342. DOI: 10.1002/eqe.995.

10. Baker JW, Cornell CA. Spectral shape, record selection and epsilon. Earthquake Engineering and Structural Dynamics 2006; 35(9):1077-1095.

11. Bradley BA. A comparison of intensity-based distributions and the seismic demand hazard for seismic performance assessment. Earthquake Engineering and Structural Dynamics 2013 (submitted).

12. Bradley BA. The seismic demand hazard and importance of the conditioning intensity measure. Earthquake Engineering and Structural Dynamics 2012; 41(11):1417-1437. DOI: 10.1002/eqe.2221.

13. NIST. Selecting and scaling earthquake ground motions for performing response-history analyses. NIST GCR 11-917-15, 2011; pp. 256.

14. Shome N, Cornell CA. Probabilistic Seismic Demand Analysis of Nonlinear Structures, Stanford University, 1999; pp. 357.

15. Tothong P, Luco N. Probabilistic seismic demand analysis using advanced ground motion intensity measures. Earthquake Engineering and Structural Dynamics 2007; 36(13):1837-1860.

16. Jalayer F, Beck JL. Effects of two alternative representation of ground-motion uncertainty on probabilistic seismic demand assessment of structures. Earthquake Engineering and Structural Dynamics 2007. DOI: 10.1002/eqe.745.

17. Bazzurro P. Probabilistic seismic demand analysis, Stanford University, 1998; 329pp.

18. Kramer SL, Mitchell RA. Ground motion intensity measures for liquefaction hazard evaluation. Earthquake Spectra 2006; 22(2):413-438.

19. Bradley BA, Dhakal RP, Cubrinovski M, MacRae GA. Prediction of spatially distributed seismic demands in structures: from structural response to loss estimation. Earthquake Engineering and Structural Dynamics 2009; 39(6):591-613. DOI: 10.1002/eqe.955.

20. Rathje EM, Saygili G. Probabilistic seismic hazard analysis for the sliding displacement of slopes: scalar and vector approaches. Journal of Geotechnical and Geoenvironmental Engineering 2008; 134(6):804-814. DOI: 10.1061/ (ASCE)1090-0241(2008)134:6(804).

21. Aslani H, Miranda E. Probability-based seismic response analysis. Engineering Structures 2005; 27(8):1151-1163.

22. Krawinkler H, Miranda E. Performance-based Earthquake Engineering. Earthquake Engineering: From Engineering Seismology to Performance-based Engineering, Bozorgnia Y, Bertero VV (eds). CRC Press: Boca Raton, FL, 2004.

23. Zareian F, Krawinkler H. Assessment of probability of collapse and design for collapse safety. Earthquake Engineering and Structural Dynamics 2007; 36(13):1901-1914.

24. Mackie KR, Stojadinovic B. Performance-based seismic bridge design for damage and loss limit states. Earthquake Engineering and Structural Dynamics 2007; 36(13):1953-1971. DOI: 10.1002/eqe.699.

25. Baker JW, Cornell CA. Uncertainty Specification and Propagation for Loss Estimation Using FOSM Method, 2003; pp. 100.

26. Bradley BA, Dhakal RP. Error estimation of closed-form solution for annual rate of structural collapse. Earthquake Engineering and Structural Dynamics 2008; 37(15):1721-1737. 
27. Bradley BA, Lee DS. Accuracy of approximate methods of uncertainty propagation in loss estimation. Structural Safety 2009; 32(1):13-24. DOI: 10.1016/j.strusafe.2009.04.001.

28. Dolšek M, Fajfar P. Simplified probabilistic seismic performance assessment of plan-asymmetric buildings. Earthquake Engineering and Structural Dynamics 2007; 36(13):2021-2041. DOI: 10.1002/eqe.697.

29. Fajfar P, Dolšek M. A practice-oriented estimation of the failure probability of building structures. Earthquake Engineering and Structural Dynamics 2012; 41(3):531-547. DOI: 10.1002/eqe.1143.

30. Eads L, Miranda E, Krawinkler H, Lignos DG. An efficient method for estimating the collapse risk of structures in seismic regions. Earthquake Engineering and Structural Dynamics 2013; 42(1):25-41. DOI: 10.1002/eqe.2191.

31. Dolšek M. Simplified method for seismic risk assessment of buildings with consideration of aleatory and epistemic uncertainty. Structure and Infrastructure Engineering 2012; 8(10):939-953. DOI: 10.1080/15732479.2011.574813.

32. Fragiadakis M, Vamvatsikos D. Fast performance uncertainty estimation via pushover and approximate IDA. Earthquake Engineering and Structural Dynamics 2010; 39(6):683-703. DOI: 10.1002/eqe.965.

33. Bradley BA, Lee DS, Broughton R, Price C. Efficient evaluation of performance-based earthquake engineering equations. Structural Safety 2009; 31(1):65-74. DOI: 10.1016/j.strusafe.2008.03.003.

34. Bradley BA. A ground motion selection algorithm based on the generalized conditional intensity measure approach. Soil Dynamics and Earthquake Engineering 2012; 40(0):48-61. DOI: 10.1016/j.soildyn.2012.04.007.

35. Aslani H, Miranda E. Fragility assessment of slab-column connections in existing non-ductile reinforced concrete buildings. Journal of Earthquake Engineering 2005; 9(6):777-804.

36. Bradley BA, Dhakal RP, Cubrinovski M, MacRae GA. Prediction of spatially distributed seismic demands in structures: ground motion and structural response. Earthquake Engineering and Structural Dynamics 2009; 39(5):501-520. DOI: 10.1002/eqe.954.

37. Ramirez CM, Miranda E. Building-specific loss estimation methods and tools for simplified performance-based earthquake engineering, Stanford University, Blume Centre report number 171, 2009; pp. 370.

38. Bowen H, Cubrinovski M. Effective stress analysis of piles in liquefiable soil: a case study of a bridge foundation. Bulletin of the New Zealand Society for Earthquake Engineering 2008; 41(4):247-262.

39. Bradley BA, Cubrinovski M, Dhakal RP, MacRae GA. Probabilistic seismic performance and loss assessment of a bridge-foundation-soil system. Soil Dynamics and Earthquake Engineering 2009; 30(5):395-411. DOI: 10.1016/ j.soildyn.2009.12.012.

40. Shome N, Cornell CA, Bazzurro P, Carballo JE. Earthquakes, records, and nonlinear responses. Earthquake Spectra 1998; 14(3):469-500.

41. Cornell CA, Jalayer F, Hamburger RO, Foutch DA. Probabilistic basis for 2000 SAC federal emergency management agency steel moment frame guidelines. Journal of Structural Engineering 2002; 128(4):526-533.

42. FEMA-350. Recommended seismic design criteria for new steel moment-frame buildings, SAC Joint Venture, 2000; pp.

43. SEAOC. Vision 2000: a framework for performance-based design, Structural Engineers Association of California, 1995; pp.

44. ATC-40. Seismic evaluation and retrofit of concrete buildings, Volume 1, 1996; pp. 